\title{
Sobrevivência de Acidovorax avenae subsp. citrulli em Meloeiro*
}

\author{
Valter A.V. Silva ${ }^{1 *}$, Elineide B. Silveira ${ }^{2} \&$ Rosa L.R. Mariano ${ }^{1^{*}}$ \\ ${ }^{1}$ Departamento de Agronomia, Área de Fitossanidade; ${ }^{2}$ Departamento de Biologia/Microbiologia, Universidade Federal \\ Rural de Pernambuco, CEP 52171-030, Recife, PE, e-mail: elineidebs@yahoo.com.br
}

(Aceito para publicação em 31/08/2006)

Autor para correspondência: Elineide B. Silveira

SILVA, V.A.V., SILVEIRA, E.B. \& MARIANO, R.L.R. Sobrevivência de Acidovorax avenae subsp. citrulli em meloeiro. Fitopatologia Brasileira 31:381-386. 2006.

\begin{abstract}
RESUMO
A capacidade de Acidovorax avenae subsp. citrulli sobreviver epifítica e endofíticamente nas folhas e raízes, bem como na rizosfera de meloeiro, foi determinada utilizando um isolado mutante resistente a rifampicina ( Aacl $^{\text {Rif }}$ ). Folhas de meloeiros com 18 dias, cultivados em casa de vegetação e no campo, foram pulverizadas com suspensões do mutante nas concentrações $\left(3,4 \times 10^{2}, 3,4 \times 10^{3}\right.$ e 3,4 x $\left.10^{4} \mathrm{ufc}^{-\mathrm{ml}^{-1}}\right)$. Para determinar a sobrevivência em raízes e na rizosfera sementes de melão Amarelo híbrido AF-682 foram semeadas em solo infestado com suspensões de Aacl $^{\text {Rif }}$ a 3,4 x $10^{5}, 3,4 \times 10^{6}$ e $3,4 \times 10^{7}$ ufc.ml ${ }^{-1}$. A cada seis dias, amostras de folhas, raízes e solo rizosférico foram coletadas e processadas para isolamento em meio de ágar nutritivo + extrato de levedura + dextrose contendo rifampicina. As populações bacterianas foram determinadas em ufc. $\mathrm{g}^{-1}$ de amostra e os dados obtidos transformados em $\log _{10}$ para análise de regressão. Nas folhas de meloeiro, em casa-de-vegetação e campo, o mutante $A a c l^{\text {Rif }}$ sobreviveu epifiticamente durante 54 dias, observando-se inicialmente aumento da população bacteriana epifítica, com posterior declínio, sendo as populações finais semelhantes nas duas condições estudadas, com valores variando de $10^{3}$ a $10^{4} \mathrm{ufc} \cdot \mathrm{g}^{-1}$ de folha, independente da concentração do inóculo inicial. Nas raízes e rizosfera, em casa-de-vegetação, a população bacteriana decresceu ao longo do tempo até atingir aos 60 dias após a infestação do solo, níveis de $10^{2}$ a $10^{3}$ ufc. $\mathrm{g}^{-1}$ de raiz e $10^{1}$ ufc. $\mathrm{g}^{-1}$ de solo. Aac $\mathrm{C}^{\text {Rif }}$ não foi detectado sobrevivendo endofiticamente em folhas ou raízes de meloeiro.
\end{abstract}

Palavras-chave adicionais: Cucumis melo, mancha-aquosa, ecologia de bactérias fitopatogênicas, fitobactéria.

\begin{abstract}
Survival of Acidovorax avenae subsp. citrulli on melon plants.

The ability of Acidovorax avenae subsp. citrulli to survive epiphytically and endophytically on leaves, roots and rhizosphere of melon plants was determined by using a mutant resistant to rifampicin (Aacl ${ }^{\text {Rif }}$ ). Leaves of 18-day-old melon plants grown in greenhouse and field were sprayed with mutant suspensions at concentrations of $3.4 \times 10^{2}, 3.4$ x $10^{3}$ and $3.4 \times 10^{4}$ cfu.ml ${ }^{-1}$. To determine survival on roots and rhizosphere, seeds of Yellow melon were sown in soil infested with suspensions of $\mathrm{Aacl}^{\mathrm{Rif}}$ at $3.4 \times 10^{5}, 3.4 \times 10^{6}$ and $3.4 \times 10^{7} \mathrm{cfu}^{\mathrm{m} l^{-1}}$. At 6-day intervals samples of leaves, roots and rhizosphere soil were collected and processed for isolation on NYDA medium amended with rifampicin. Bacterial populations were determined as cfu. $\mathrm{g}^{-1}$ of sample and the data were transformed to $\log _{10}$ for regression analysis. On melon leaves, in greenhouse and field $A a c l^{\text {Rif }}$ survived epiphytically for 54 days. These epiphytic bacterial populations increased initially and decreased after a certain period of time. Both final populations were similar under the two conditions and ranged from $10^{3}$ to $10^{4} \mathrm{cfu} . \mathrm{g}^{-1}$ of leaf, without correlation with the inoculum concentration used. In greenhouse, bacterial populations on the roots and rhizosphere decreased with time, and 60 days after soil infestation they ranged from $10^{2}$ to $10^{3} \mathrm{cfu} . \mathrm{g}^{-1}$ of roots and $10^{1} \mathrm{cfu} . \mathrm{g}^{-1}$ of soil. Aacl ${ }^{\text {Rif }}$ was not detected as an endophyte in leaves or roots of melon plants.
\end{abstract}

Additional keywords: Cucumis melo, Fruit blotch, ecology of bacterial plant pathogens, plant pathogenic bacteria.

\section{INTRODUÇÃO}

A mancha-aquosa do meloeiro (Cucumis melo L.) é a principal doença bacteriana que vem ocorrendo nas lavouras de melão do Nordeste, sendo responsável por grandes perdas na produção e depreciação dos frutos no Rio

\footnotetext{
*Parte da Dissertação de Mestrado do primeiro autor. Universidade Federal Rural de Pernambuco. Recife. 2005.
}

Grande do Norte e Ceará (Sales Júnior \& Menezes, 2001). É causada por Acidovorax avenae subsp. citrulli (Schaad, Sowell, Goth, Colwell \& Webb) Willems, Goor, Thielemans, Gillis, Kersters \& De Ley, uma bactéria Gram-negativa, em forma de bastonete e que pode ser transmitida por sementes de várias cucurbitáceas (Hopkins \& Thompson, 2002). Os sintomas da doença nos frutos são lesões aquosas e nos cotilédones e folhas verdadeiras, lesões necróticas (Sales Júnior \& Menezes, 2001; Santos \& Viana, 2000). 
Adisseminação dessa bactéria a longa distância ocorre, principalmente, por sementes contaminadas (O'Brien \& Martin, 1999) e pelo transplantio de mudas de cucurbitáceas infectadas (Hopkins et al., 1992). Entre plântulas ou plantas vizinhas e das folhas para os frutos, a disseminação se dá através de respingos de água de chuva e irrigação, solos infestados, insetos, utensílios agrícolas, operários de campo (Santos \& Viana, 2000) e aerossóis (Hopkins et al., 1992). A colonização de folhas e frutos de meloeiro por $A$. avenae subsp. citrulli requer alta umidade (O'Brien \& Martin, 1999), que juntamente com temperatura elevada favorecem o progresso da doença (Mariano \& Silveira, 2004).

Acidovorax avenae subsp. citrulli sobrevive durante a entressafra em restos de cultura, em hospedeiros silvestres e cultivados, em plântulas voluntárias (Latin et al., 1995; Latin \& Hopkins, 1995; Santos \& Viana, 2000; Nascimento et al., 2004), em sementes (Latin \& Hopkins, 1995; Santos \& Viana, 2000) e no solo por algumas semanas (Isakeit, 1999). Inexistem dados sobre a sobrevivência epifítica e endofítica dessa bactéria nas folhas e raízes de meloeiro, bem como sobre sua sobrevivência na rizosfera. É importante que se conheça a dinâmica populacional de $A$. avenae subsp. citrulli sobrevivendo nesses locais para que medidas eficientes de controle possam ser estabelecidas, impedindo a disseminação do patógeno.

Mutantes com resistência a antibióticos têm sido empregados em estudos ecológicos de bactérias fitopatogênicas incluindo sobrevivência no solo e em plantas. A sobrevivência de Xanthomonas campestris (Pammel) Dowson em solo foi estudada pelo uso de mutantes resistentes a rifampicina (López et al., 1999) e mutantes com resistência a rifampicinaácido nalidíxico de Pseudomonas syringae pv. syringae van Hall, P. syringae pv. tomato (Okabe) Young, Dye \& Wilkie e $P$. viridiflava (Burkholder) Dowson foram empregados para avaliar a sobrevivência epifítica em folhas e raízes de tomateiro e ervas daninhas (Mariano \& McCarter, 1991a, b; 1993).

A proposta do presente estudo foi determinar a capacidade de $A$. avenae subsp. citrulli sobreviver epifitica e endofiticamente em folhas e raízes, e na rizosfera de meloeiro.

\section{MATERIAL E MÉTODOS}

\section{Obtenção do mutante de Acidovorax avenae subsp. citrulli resistente ao antibiótico rifampicina}

Mutante espontâneo resistente ao antibiótico rifampicina foi obtido a partir do isolado $A a c 1$ de $A$. avenae subsp. citrulli, pertencente à coleção de bactérias do Laboratório de Fitobacteriologia da Universidade Federal Rural de Pernambuco. Inicialmente $0,1 \mathrm{ml}$ de suspensão bacteriana $\left(3,4 \times 10^{7}\right.$ ufc. $\left.\mathrm{ml}^{-1}\right)$ foi plaqueado em meio de cultura ágar nutritivo + extrato de levedura + dextrose (NYDA) com $50 \mathrm{ppm}$ de rifampicina. As placas foram incubadas em B.O.D. a $30^{\circ} \mathrm{C}$, por $48 \mathrm{~h}$, e a partir de uma colônia mutante resistente a $50 \mathrm{ppm}$ foi obtido, pelo mesmo método, um mutante resistente a $100 \mathrm{ppm}$ de rifampicina, denominado $A a c l^{\text {Rif }}$. Para testar a estabilidade de $A a c l^{\text {Rif }}$ foram realizadas repicagens para meio NYDA com e sem antibiótico, alternadamente por 10 vezes.

$A a c l^{\text {Rif }}$ foi comparado a $A a c l$ quanto ao crescimento em meio líquido e patogenicidade a meloeiro. Em tubos de ensaio contendo $9 \mathrm{ml}$ do meio NYD (caldo nutritivo + extrato de levedura + dextrose) foi adicionado $1 \mathrm{ml}$ da suspensão bacteriana $\left(3,4 \times 10^{7} \mathrm{ufc}^{\mathrm{ml}} \mathrm{l}^{-1}\right)$. Os tubos foram incubados em B.O.D. e o crescimento foi avaliado pela variação na densidade ótica da cultura em meio líquido, monitorada por colorimetria a $580 \mathrm{~nm}$ após, 24, 48, 96 e 144 h, com cinco repetições para cada intervalo.

Para comparar a patogenicidade de $A a c l^{\text {Rif }}$ em relação a $A a c 1$ em plantas de meloeiro foi seguida a metodologia de Silveira et al. (2003a). Foram utilizadas oito plantas por tratamento e avaliadas duas folhas por planta, do quarto ao oitavo dia após a inoculação, determinando-se a severidade da mancha-aquosa.

Sobrevivência epifítica e endofítica do mutante de Acidovorax avenae subsp. citrulli em folhas de meloeiro, sob condições de casa-de-vegetação e de campo

Plantas de meloeiro Amarelo, híbrido AF-682, foram cultivadas durante 18 dias em casa-de-vegetação, em vasos de 31 contendo a mistura 2:1 (v/v) de solo/substrato Plantmax ${ }^{\circledR}$, e em parcela experimental no campo em manilhas de cimento com diâmetro de $100 \mathrm{~cm}$ e capacidade para $45 \mathrm{~kg}$ de solo. As plantas foram inoculadas por pulverização com $A a c 1^{\text {Rif }}$ em três diferentes concentrações $\left(3,4 \times 10^{2}, 3,4 \times 10^{3}\right.$ e 3,4 × $10^{4} \mathrm{ufc}^{\mathrm{ml}}{ }^{-1}$ ) e avaliadas nove vezes em intervalos de seis dias, a partir da inoculação. No estudo da sobrevivência epifítica, em cada avaliação duas folhas inoculadas foram coletadas, cortadas em pequenos fragmentos, misturadas, pesadas e $0,5 \mathrm{~g}$ adicionados a $4,5 \mathrm{ml}$ de água destilada esterilizada (ADE) em tubos, os quais foram submetidos a banho de ultra-som (THORNTON T7) por $5 \mathrm{~min}$, na potência 10. Para a sobrevivência endofitica, os fragmentos foram desinfestados em álcool a $50 \%$, por $30 \mathrm{~s}$, e em hipoclorito de sódio a $0,7 \%$, por $3 \mathrm{~min}$, e em seguida, lavados duas vezes com ADE. A água da última lavagem foi plaqueada para comprovação da ausência de organismos epifíticos. Depois, foram transferidos para tubo de ensaio contendo $4,5 \mathrm{ml}$ de ADE, os quais também foram submetidos ao banho de ultrasom por $5 \mathrm{~min}$, na potência 10 . Os fragmentos foram então macerados e novamente submetidos ao banho de ultra-som. Nas duas situações, foram realizadas diluições seriadas até $10^{-3}$, plaqueando-se $0,1 \mathrm{ml}$ das suspensões em meio NYDA contendo $100 \mathrm{ppm}$ de Rifampicina (NYDA ${ }^{\text {Rif }}$ ), com três repetições. As placas foram incubadas por $36 \mathrm{~h}$ a $30^{\circ} \mathrm{C}$, em B.O.D., e a avaliação realizada pela contagem do número de colônias, determinando-se a população bacteriana em ufc. $\mathrm{g}^{-1}$ de folha. Para análise de regressão, os dados foram transformados em $\log _{10}$ ufc. $\mathrm{g}^{-1}$ de folha.

O solo utilizado no experimento em campo apresentava as seguintes características: $\mathrm{pH} 5,3 ; \mathrm{P}\left[\mathrm{mg} .\left(\mathrm{dm}^{3}\right)^{-}\right.$ 1] 33; $\mathrm{K}^{+}\left[\mathrm{cmol}_{\mathrm{c}} \cdot\left(\mathrm{dm}^{3}\right)^{-1}\right] \quad 0,41 ; \mathrm{Ca}^{+2}+\mathrm{Mg}^{+2}\left[\mathrm{cmol}_{\mathrm{c}} \cdot\left(\mathrm{dm}^{3}\right)^{-1}\right]$ 3,$0 ; \mathrm{Al}^{+3} 0,35$. Para adequar as exigências da cultura, o $\mathrm{pH}$ 
do solo foi ajustado para 6,5-7,0, utilizando-se calcário.

Sobrevivência epifítica e endofítica do mutante de Acidovorax avenae subsp. citrulli em raízes e sobrevivência na rizosfera de meloeiro, sob condições de casa-devegetação

Sementes de melão do híbrido AF-682 foram semeadas em copos plásticos com capacidade de $250 \mathrm{ml}$ contendo a mistura 2:1 (v/v) solo/substrato Plantmax ${ }^{\circledR}$, infestada no momento da semeadura com suspensões de $A a c l^{\text {Rif }}$ nas concentrações de $3,4 \times 10^{5}, 3,4 \times 10^{6}$ e $3,4 \times$ $10^{7}$ ufc.ml $^{-1}$, na proporção de $40 \mathrm{ml}$ de suspensão para 200 g da mistura. Doze dias após, as mudas em torrão foram transplantadas para vasos de 3,5 1 contendo a mesma mistura. A sobrevivência epifítica e endofítica nas raízes e a sobrevivência na rizosfera de meloeiro foram avaliadas em intervalos de seis dias, a partir de plantas com 12 dias, ou seja, no momento do transplantio, conforme metodologia já descrita para folhas, utilizando as raízes ou o solo rizosférico.

\section{Análises estatísticas}

Os dados dos experimentos de sobrevivência foram submetidos à análise de regressão para selecionar modelos ajustados às curvas de sobrevivência de $A a c l^{\text {Rif }}$, com base no coeficiente de determinação $\left(\mathrm{R}^{2}\right)$ e no quadrado médio do resíduo (QMR), utilizando-se o programa TableCurve ${ }^{\mathrm{TM}} 2 \mathrm{D}$ para Windows, Verão 5.01 (SYSTAT Software Inc., USA, 2002).

\section{RESULTADOS E DISCUSSÃO}

\section{Obtenção de mutante de Acidovorax avenae subsp. citrulli resistente ao antibiótico rifampicina}

O mutante espontâneo $A a c 1^{\mathrm{Rif}}$ de $A$. avenae subsp. citrulli resistente a $100 \mathrm{ppm}$ de rifampicina mostrou estabilidade para resistência ao antibiótico, além de apresentar crescimento em NYD (Figura 1A) e causar doença em plantas de meloeiro com severidade (Figura 1B) semelhante ao isolado não resistente ao antibiótico. Resposta semelhante foi obtida para mutantes Rif-Nal de $P$. syringae pv. syringae, P. syringae pv. tomato e P. viridiflava (Mariano \& McCarter, 1991 a, b; 1993) e Sphingomonas suberifaciens (van Bruggen, Jochimsen \& Brown) Yabuuchi, Kosako, Naka, Suzuki \& Yano (O'Brien \& Van Bruggen, 1991). Embora existam evidências de que o método de marcação por resistência a antibióticos para o estudo da dinâmica das populações bacterianas pode afetar a biologia dos organismos (Schroth, 1992), neste trabalho não foram observadas diferenças marcantes entre o mutante e o isolado selvagem.

Sobrevivência epifítica e endofítica do mutante de Acidovorax avenae subsp. citrulli em folhas de meloeiro, em casa-de-vegetação e campo

Os estudos de casa-de-vegetação e campo mostraram que o mutante $A a c 1^{\text {Rif }}$ sobreviveu epifiticamente nas folhas de meloeiro durante os 54 dias de duração do experimento

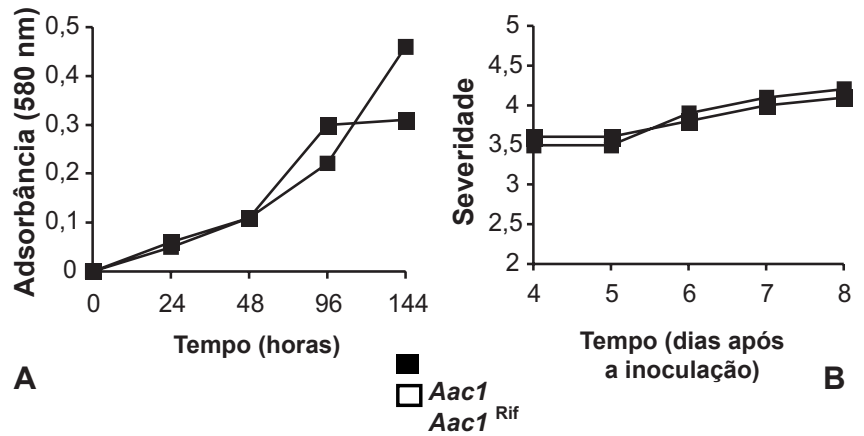

FIG. 1 - Comparação de um isolado selvagem (Aacl) e mutante (Aacl ${ }^{\text {Rif }}$ ) de Acidovorax avenae subsp. citrulli quanto ao crescimento em meio de cultura líquido A. severidade da mancha-aquosa em plantas de meloeiro; B. avaliados respectivamente pela absorbância a $580 \mathrm{~nm}$ e severidade, em diferentes períodos de tempo.

(Figura 2). O tempo de sobrevivência de bactérias fitopatogênicas no filoplano é variável. Como exemplos, em experimentos de campo, mutante Rif-Nal de $P$. syringae pv. syringae foi detectado sobrevivendo epifiticamente em folhas de tomateiro por apenas 14 dias, com populações variando de 2,5 x $10^{2}$ e 5,0 x $10^{2}$ ufc. $\mathrm{g}^{-1}$ de folha (Mariano \& McCarter, 1991b), enquanto mutantes Rif-Nal de P. syringae pv. tomato e P. viridiflava sobreviveram por 28 dias (Mariano \& McCarter, 1991a; 1993).

Em casa-de-vegetação e campo, observou-se na primeira avaliação, seis dias após a inoculação, uma elevação nas populações principalmente em condições de casa-de-vegetação (Figura 2). Este aumento continuou até $18 \mathrm{~h}$ ou $30 / 36 \mathrm{~h}$ após a inoculação, respectivamente em casade-vegetação e campo, independente da concentração da suspensão inoculada, quando então começou a declinar. No entanto, em campo, as populações nessa fase de crescimento foram menores, indicando que a pré-adaptação de $A a c l^{\mathrm{Rif}}$ ao ambiente do filoplano requereu mais tempo que em casa-devegetação para o ajuste às condições físicas e nutricionais, antes da multiplicação. Outras bactérias, a exemplo de Pseudomonas syringae van Hall, apresentam habilidade de pré-adaptação ao ambiente do filoplano (Wilson \& Lindow, 1993).

Ao contrário do esperado, aos 54 dias após a inoculação, as populações epifíticas do patógeno nas folhas de meloeiro em campo foram semelhantes àquelas encontradas nas plantas mantidas em casa-de-vegetação, variando na ordem de $10^{3}$ a $10^{4}$ ufc. $\mathrm{g}^{-1}$ de folha (Figura 2). Isto pode ter sido conseqüência das condições de temperatura $\left(28,7^{\circ} \mathrm{C}\right.$ e $\left.25,17^{\circ} \mathrm{C}\right)$ e umidade relativa $(66,78 \%$ e $76,57 \%)$ registradas em casa-de-vegetação e campo, respectivamente. Adicionalmente, a superfície da folha é vista como um ambiente hostil para os microrganismos, sujeitos nesse local a flutuações extremas de temperatura, radiação ultravioleta e visível e a períodos de dessecação (Hirano \& Upper, 1983), principalmente em condições de campo. O nível populacional similar do mutante $A a c l^{\text {Rif }}$ em casa-de-vegetação e campo sugere sua habilidade de evitar a dessecação e a ação da luz ultravioleta, características estas importantes para a 


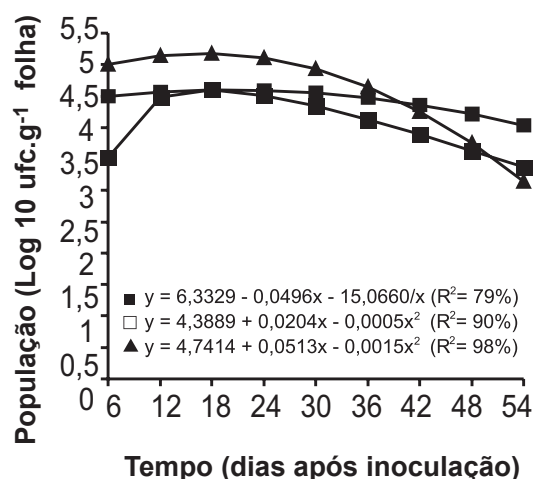

Tempo (dias após inoculação)
Casa de Vegetação $\quad \square, 4 \times 10^{2}$ ufc.ml $^{1}$
$\quad \square, 4 \times 10^{3}$ ufc.ml $^{-1}$

$\Delta 3,4 \times 10^{4}$ ufc. $\mathrm{ml}^{-1}$

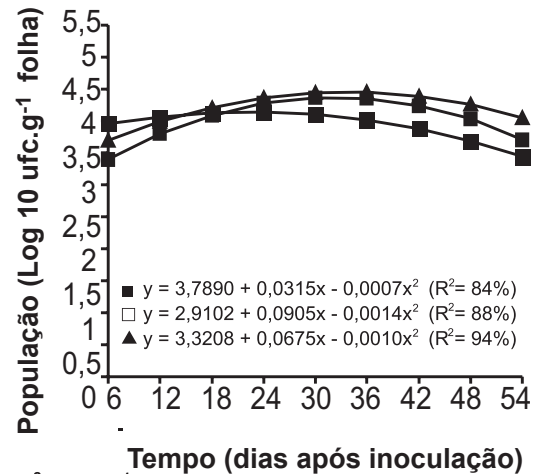

FIG. 2 - Sobrevivência epifítica de Acidovorax avenae subsp. citrulli resistente a rifampicina ( $A a c l^{\mathrm{Rif}}$ ), inoculada em três concentrações nas folhas de meloeiro, avaliada em diferentes períodos de tempo, em casa-de-vegetação e em campo.

sobrevivência (Beattie \& Lindow, 1999). Células de $A$. avenae subsp. citrulli geralmente permanecem agregadas e muito raramente isoladas na superfície das folhas de melão (Silva Neto et al., 2006), sendo a agregação de células uma característica que aumenta a chance de sobrevivência porque protege células individuais da dessecação (Denny, 1995). A presença de fibrilas nas células de $A$. avenae subsp. citrulli interligando-as a superfície do hospedeiro (Silva Neto et al., 2006) também favorece a sobrevivência no filoplano por proporcionar a aderência das células ao tecido da planta e, desta forma, diminuir o impacto de fatores mecânicos como o vento e a chuva sobre a disseminação da bactéria. Segundo Silva Neto et al. (2006), as células dessa bactéria situamse preferencialmente em locais protegidos do filoplano, tais como depressões existentes entre as células epidermais, base dos tricomas e ao redor e dentro dos estômatos. Este fato tem sido evidenciado pela microscopia eletrônica de varredura para estudos de sobrevivência em outras interações patógeno hospedeiro (Mariano \& McCarter, 1991 a, b; 1993).

Em relação à tendência da sobrevivência de $A a c l^{\text {Rif }}$ nas folhas de meloeiro, observou-se que a variação populacional ao longo do tempo apresentou de maneira geral comportamento semelhante para todas as concentrações inoculadas, seja em condições de casa-de-vegetação ou

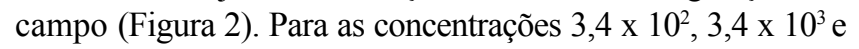
$3,4 \times 10^{4} \mathrm{ufc}^{-\mathrm{ml}^{-1}}$ inoculadas em plantas em casa-de-vegetação os modelos: $\mathrm{y}=6,3329-0,0496 \mathrm{x}-15,0660 / \mathrm{x}\left(\mathrm{R}^{2}=79 \%\right)$; $y=4,3889+0,0204 x-0,0005 x^{2}\left(R^{2}=90 \%\right) ; y=4,7414+$ $0,0513 x-0,0015 x^{2}\left(R^{2}=98 \%\right)$, respectivamente, descreveram adequadamente a variação ocorrida na sobrevivência da bactéria. Em condições de campo, os modelos: y $=3,7890$ $+0,0315 \mathrm{x}-0,0007 \mathrm{x}^{2}\left(\mathrm{R}^{2}=84 \%\right) ; \mathrm{y}=2,9102+0,0905 \mathrm{x}-$ $0,0014 \mathrm{x}^{2}\left(\mathrm{R}^{2}=88 \%\right) ; \mathrm{y}=3,3208+0,0675 \mathrm{x}-0,0010 \mathrm{x}^{2}\left(\mathrm{R}^{2}=\right.$ 94\%) apresentaram bons ajustes às curvas de sobrevivência em função da concentração do inóculo inicial de $3,4 \times 10^{2}, 3,4 \times 10^{3}$ e $3,4 \times 10^{4}$ ufc. $\mathrm{ml}^{-1}$, respectivamente.

Em campo, não foram observados sintomas da mancha-aquosa nas folhas inoculadas com Aacl $^{\mathrm{Rif}}$, embora em casa-de-vegetação tenha sido observada incidência baixa da doença. Silveira et al. (2003b) utilizando as mesmas concentrações e outros isolados de $A$. avenae subsp. citrulli verificaram índice de doença em torno de $15 \%$ em plantas com 20 dias, avaliadas oito dias após a inoculação. Esta diferença de resultados pode ser explicada pela ausência de incubação das plantas em câmara úmida $48 \mathrm{~h}$ antes e após inoculação. Desta forma, a bactéria não encontrou condições favoráveis para penetrar através dos estômatos e causar infecção. As bactérias fitopatogênicas são capazes de sobreviver e se multiplicar sobre superfícies de plantas sem causar sintomas (Lebben, 1965). Sintomas do crestamento comum do feijoeiro só ocorrerem quando as populações residentes de $X$. campestris pv. phaseoli (Smith) Dye excedem o nível de $5 \times 10^{6}$ ufc.folíolo $^{-1}$ (Hirano \& Upper, 1983).

O fato citado acima em relação à penetração da bactéria, também deve ter contribuído para que $A a c 1^{\mathrm{Rif}}$ não tenha sido detectada colonizando endofiticamente as folhas de meloeiro. Outro aspecto a ser considerado é que o método de isolamento utilizado pode não ter sido eficiente para detectar a população endofítica que, se existente, estaria em baixos níveis. Em estudos de microscopia eletrônica de varredura utilizando folhas de meloeiro inoculadas com o mesmo isolado Aacl na concentração de $3,4 \times 10^{7}$ ufc.ml $^{-1}$, células da bactéria foram encontradas endofiticamente colonizando os espaços intercelulares da folha (Silva Neto et al., 2006).

No presente trabalho, sugere-se que as populações epifiticas encontradas nas folhas de meloeiro são parcialmente responsáveis pela sobrevivência local da bactéria e pela manutenção do inóculo na ausência de condições favoráveis à infecção. Estas populações epifíticas são fonte primária de inóculo e o fato de existirem em plantas sem sintomas representa um grande risco na disseminação da bactéria dentro de um plantio ou na introdução do patógeno em áreas indenes, favorecendo a ocorrência de epidemias. 
Sobrevivência epifítica e endofítica do mutante de Acidovorax avenae subsp. citrulli em raízes e sobrevivência na rizosfera de meloeiro

Doze dias após a infestação do solo, as populações de $A a c 1^{\text {Rif }}$ detectadas nas raízes decresceram em relação às populações introduzidas, em todas as concentrações, enquanto que na rizosfera observou-se um aumento de população nas concentrações $3,4 \times 10^{6}$ e $3,4 \times 10^{7}$ ufc.g $^{-1}$ de solo (Figura 3). O aumento das populações detectado na rizosfera aos 12 dias pode ter sido causado pela alteração dos exsudados radiculares durante a transição do estádio cotiledonar para o estádio fotossintético (Schuster \& Coyne, 1974). Ao longo do tempo, as populações decresceram até atingir aos 60 dias após infestação do solo níveis em torno de $10^{2}$ a $10^{3}$ ufc. $\mathrm{g}^{-1}$ de raiz e $10^{1}$ ufc. $\mathrm{g}^{-1}$ de solo. Uma população bacteriana no solo pode ser reduzida por inanição, competição com outras bactérias e lise (Ace et al., 1988), além da inibição pela microbiota antagonista e influência das características físicas e químicas do solo (Schuster \& Coyne, 1974).

Os modelos: $\mathrm{y}=3,3482+0,0054 \mathrm{x}-0,0003 \mathrm{x}^{2}\left(\mathrm{R}^{2}\right.$ $=97 \%) ; \mathrm{y}=5,2917-0,0977 \mathrm{x}+0,0008 \mathrm{x}^{2}\left(\mathrm{R}^{2}=86 \%\right)$ e $\mathrm{y}$ $=5,4421-0,1013 \mathrm{x}+0,0009 \mathrm{x}^{2}\left(\mathrm{R}^{2}=93 \%\right)$, descreveram adequadamente a variação ocorrida, quanto a sobrevivência nas raízes das concentrações $3,4 \times 10^{5}, 3,4 \times 10^{6}$ e $3,4 \times 10^{7}$ ufc. $\mathrm{ml}^{-1}$, respectivamente. Na rizosfera, os modelos: $\mathrm{y}=3,3446$ $+0,2230 \mathrm{x}-0,0104 \mathrm{x}^{2}+0,0001 \mathrm{x}^{3}\left(\mathrm{R}^{2}=94 \%\right) ; \mathrm{y}=-2,0678$ $+140,028 / \mathrm{x}\left(\mathrm{R}^{2}=99 \%\right)$ e $\mathrm{y}=-2,1787+157,4622 / \mathrm{x}\left(\mathrm{R}^{2}=\right.$ $89 \%$ ), apresentaram bom ajuste às curvas de sobrevivência em função das concentrações iniciais de 3,4 x 10 5 , 3,4 x $10^{6}$ e 3,4 x $10^{7}$ ufc. $\mathrm{ml}^{-1}$, respectivamente.

Em geral, diferença da ordem de $10^{1}$ ufc. $\mathrm{g}^{-1}$ foi observada entre a sobrevivência epifítica de $A a c 1^{\text {Rif }}$ nas folhas e raízes de meloeiro, em casa-de-vegetação (Figuras 2 e 3). Acidovorax avenae subsp. citrulli é um patógeno habitante da parte aérea e como tal sobreviveu melhor nas folhas do que nas raízes. Contudo, outras bactérias habitantes da parte aérea de plantas como $P$. syringae pv. tomato e $P$. syringae pv. syringae sobreviveram melhor nas raízes do que nas folhas de tomateiro (Mariano \& McCarter, 1991a, b). Nesse ambiente $P$. syringae pv. syringae sobreviveu epifiticamente por 28 dias (Mariano \& McCarter, 1991b). A presença de sítios nutricionais mais adequados e especialmente um ambiente físico mais estável no rizoplano podem explicar a preferência da sobrevivência nas raízes em relação às folhas em alguns casos (Dickinson, 1971). Geralmente, acreditase que patógenos de folhagem não são bem adaptados a sobreviver no solo (Hirano \& Upper, 1983), o que poderia explicar a baixa sobrevivência de $A a c 1^{\text {Rif }}$ na rizosfera (Figura 3). Destaca-se que o método de isolamento empregado foi eficiente para detectar baixas populações da bactéria no solo. Em melão, não foram encontradas informações sobre a sobrevivência de $A$. avenae subsp. citrulli no solo sem planta hospedeira e em restos de cultura deixados no campo, embora segundo Isakeit (1999) o patógeno aparentemente sobreviva no solo por poucas semanas durante o verão na ausência da melancia . Em restos de cultura, a bactéria foi recuperada de fragmentos de casca de melancia enterrados por 10 meses a uma profundidade de 20 a $30 \mathrm{~cm}$ (Latin et al., 1995).

A bactéria também não foi detectada colonizando endofiticamente as raízes de plantas de meloeiro. Sintomas da mancha-aquosa nunca foram observados em raízes de meloeiro ou de outras hospedeiras dessa bactéria. Através de microscopia eletrônica, A. avenae subsp. citrulli também não foi visualizada no xilema e floema de plântulas de melancia infectadas (Walcott et al., 2003).

A comprovação da habilidade da bactéria sobreviver epifiticamente no mínimo por 60 dias nas raízes e na rizosfera de meloeiro, reforça a importância da aplicação de algumas medidas de controle, tais como: erradicar plantas voluntárias (Dias et al., 1998); destruir restos de culturas, principalmente em campos com plantas infectadas (O’Brien \& Martin, 1999); eliminar outras hospedeiras alternativas (Nascimento et al., 2004), nas quais a bactéria, provavelmente, também sobrevive no rizoplano e rizosfera, além do filoplano.

As informações obtidas neste trabalho sobre a dinâmica populacional de $A$. avenae subsp. citrulli
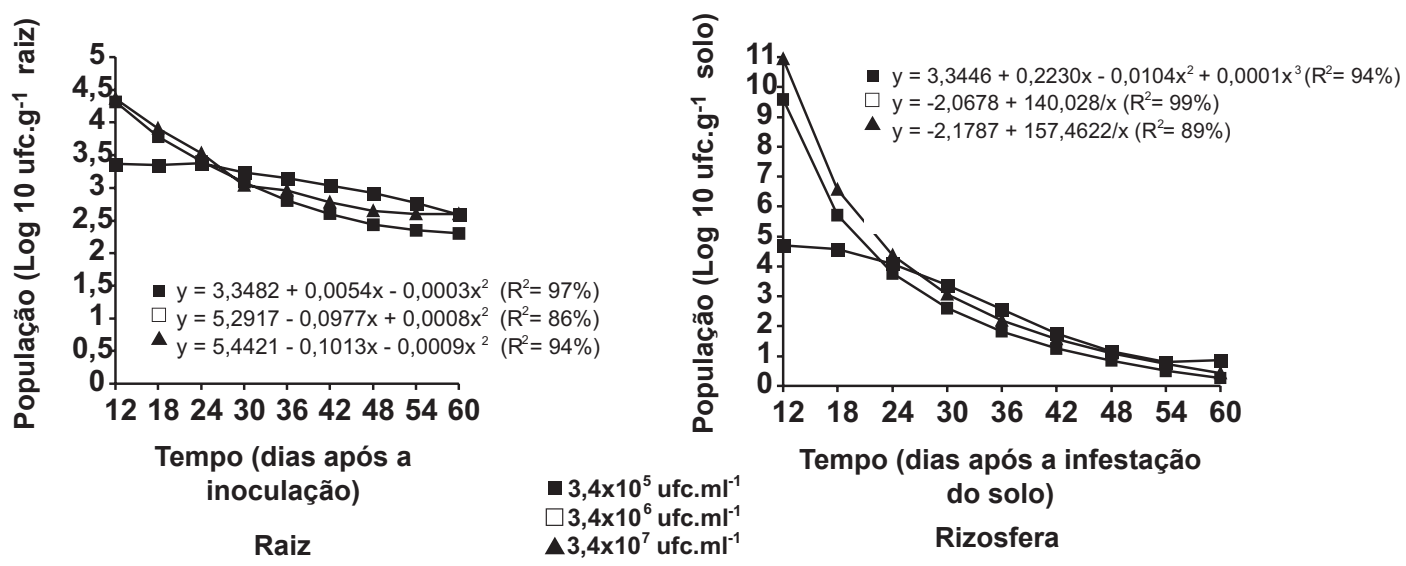

FIG. 3 - Sobrevivência epifítica na raiz e sobrevivência na rizosfera de meloeiro de Acidovorax avenae subsp. citrulli resistente a rifampicina $\left(A a c l^{\text {Rif }}\right)$, introduzida no solo em três concentrações, avaliada em diferentes períodos de tempo em casa-de-vegetação. 
sobrevivendo epifiticamente nas folhas e raízes, e na rizosfera do meloeiro, são de fundamental importância para o esclarecimento de diversos aspectos relacionados a ecologia e epidemiologia da mancha-aquosa e a aplicabilidade de medidas de controle.

\section{AGRADECIMENTOS}

Ao CNPq pela concessão da bolsa de mestrado ao primeiro autor e bolsa de pesquisa ao último autor.

\section{REFERÊNCIAS BIBLIOGRÁFICAS}

ACE, M.J., MOORE, C.R. \& ALEXANDER, M. Survival and growth of bacteria introduced into soil. Soil Biology and Biochemistry 20:509-515. 1988.

BEATTIE, G.A. \& LINDOW, S.E. Bacterial colonization of leaves: a spectrum of strategies. Phytopathology 89:353-359. 1999.

DENNY, T.P. Involvement of bacterial polysaccharides in plant pathogenesis. Annual Review of Phytopathology 33:173-197. 1995.

DIAS, R.C.S., COSTA, N.D., CERDAN, C., SILVA, P.C.G., QUEIROZ, M.A., ZUZA, F., KEITE, L.A.S., PESSOA, P.F.A.P. \& TERAO, D.A. Cadeia produtiva do melão no Nordeste. In: Castro, A.M.G., Lima, S.M.V., Goedert, W.J., Freitas Filho, A. \& Vasconcelos, J.R.P. (Eds.) Cadeias produtivas e sistemas naturais: prospeções tecnológicas. Brasília. EMBRAPA SPI. 1998. pp. 440-493.

DICKINSON, C.H. Cultural studies of leaf saprophytes. In: Preece, T.R. \& Dickinson, C.H. (Eds.) Ecology of leaf surface microrganisms. London. Academic Press. 1971. pp. 129-137.

HIRANO, S.S. \& UPPER, C.D. Ecology and epidemiology of foliar bacterial pathogens. Annual Review of Phytopathology 21:243-269. 1983.

HOPKINS, D.L. \& THOMPSON, C.M. Evaluation of Citrullus sp. germplasm for resistance to Acidovorax avenae subsp. citrulli. Plant Disease 86:61-64. 2002.

HOPKINS, D.L., STALL, R.E., LATIN, R., RUSHING, J., COOK, W.P. \& KEINATH, A.P. Bacterial fruit blotch of watermelon. Gainesville. American Sunmelon. 1992. 4p. (Bulletin).

ISAKEIT, T. Bacterial fruit blotch of watermelon. Texas. Agricultural Extension Service. 1999. 2p. (Publication L-5222).

LATIN, R. \& HOPKINS, D.L. Bacterial fruit blotch of watermelon. The hypothetical exam question becomes reality. Plant Disease 79:761-765. 1995.

LATIN, R., TIKHONOVA, I. \& RANE, K. Factors affecting the survival and spread of Acidovorax avenae subsp. citrulli in watermelon transplant production facilities. Phytopathology 85:1413-1417. 1995.

LEBBEN, C. Epiphytic microrganisms in relation to plant disease. Annual Review of Phytopathology 3:209-230. 1965.

LÓPEZ, N.I., HAEDO, A.S. \& MÉNDEZ, B.S. Evaluation of Xanthomonas campestris survival in a soil microcosm system. International Microbiology 2:111-114. 1999.
MARIANO, R.L.R. \& MCCARTER, S.M. Epiphytic survival of Pseudomonas syringae pv. tomato on tomato and weeds. Fitopatologia Brasileira 16:86-91. 1991a.

MARIANO, R.L.R. \& MCCARTER, S.M. Epiphytic survival of Pseudomonas syringae pv. syringae on tomato and weeds. Fitopatologia Brasileira 16:92-97. $1991 \mathrm{~b}$.

MARIANO, R.L.R. \& MCCARTER, S.M. Epiphytic survival of Pseudomonas viridiflava on tomato and selected weed species. Microbial Ecology 26:47-58. 1993.

MARIANO, R.L.R. \& SILVEIRA, E.B. Mancha-aquosa: importante bacteriose do meloeiro no Brasil. Anais da Academia Pernambucana de Ciência Agronômica 1:79-88. 2004.

NASCIMENTO, A.R.P., MARIANO, R.L.R. \& SILVA, E.I. Hospedeiros alternativos de Acidovorax avenae subsp. citrulli. Horticultura Brasileira 22:345-349. 2004.

O'BRIEN, R.G. \& MARTIN, A.L. Bacterial blotch of melons caused by strains of Acidovorax avenae subsp. citrulli. Australian Journal of Experimental Agriculture 39:479-485. 1999.

O'BRIEN, R.G. \& VAN BRUGGEN, H.C. Populations of Rhizomonas suberifaciens on roots of host and nonhost plants. Ecology and Epidemiology 81:1034-1038. 1991.

SALES JÚNIOR, R. \& MENEZES, J.B. Mapeamento das doenças fúngicas, bacterianas e viróticas do cultivo do melão no Estado do RN. Mossoró. Escola Superior de Agricultura de Mossoró. 2001. 25p. (Relatório Técnico).

SANTOS, A.A. \& VIANA, F.M. Mancha-aquosa do melão. Fortaleza. EMBRAPA-SPI. 2000. 2p. (Impresso)

SCHROTH, M.N. Risks of releasing wild-type and genetically engineered biocontrol organisms into the ecosystem. In: Tjamos, E.S., Papavizas, G.C. \& Cook, R.J. (Eds.). Biological control of plant diseases. New York. Plenum Press. 1992. pp. 371-379.

SILVA NETO, E.B., SILVEIRA, E.B., MARIANO, R.L.R., NOGUEIRA, N. L., ROSSI, M.L. \& SANTOS, L.A. Penetração e colonização de Acidovorax avenae subsp. citrulli em folhas, frutos e sementes de melão amarelo. Fitopatologia Brasileira 31:84-88. 2006.

SILVEIRA, E.B., MARIANO, R.L.R. \& MICHEREFF, S.J. Variabilidade de isolados de Acidovorax avenae subsp. citrulli no estado do Rio Grande do Norte. Summa Phytopathologica 29:255261. 2003a.

SILVEIRA, E.B., MICHEREFF, S.J. \& MARIANO, R.L.R. Severidade da mancha-aquosa em meloeiro sob diferentes condições de molhamento foliar e concentração de inóculo de Acidovorax avenae subsp. citrulli. Fitopatologia Brasileira 28:171175. $2003 \mathrm{~b}$.

SCHUSTER, M.L. \& COYNE, D.P. Survival mechanisms of phytopatogenic bacteria. Annual Review of Phytopathology 12:199-221. 1974.

WALCOTT, R.R., GITAITIS, R.D. \& CASTRO, A.C. Role blossoms in watermelon seed infestation by Acidovorax avenae subsp. citrulli. Phytopathology 93:528-534. 2003.

WILSON, M. \& LINDOW, S.E. Effect of phenotypic plasticity of epiphytic survival and colonization by Pseudomonas syringae. Applied and Environmental Microbiology 59:410-416. 1993. 